Revista

A Cor

das Letras

\title{
A lâmpada do desejo: uma leitura do conto A fuga de Clarice Lispector
}

\author{
The wishing lamp: a reading of A fuga by Clarice Lispector
}

\author{
Alana de Oliveira Freitas El Fahl* \\ Universidade Estadual de Feira de Santana, \\ Feira de Santana, Bahia, Brasil \\ Flávia Aninger de Barros Rocha** \\ Universidade Estadual de Feira de Santana, \\ Feira de Santana, Bahia, Brasil
}

\begin{abstract}
Resumo: O presente trabalho propõe-se a analisar o conto A Fuga, de Clarice Lispector, escrito em 1940 e publicado em A Bela e a Fera (1979), à luz dos conceitos freudianos do Princípio do Prazer e do Princípio da Realidade e outras ideias também desenvolvidas no texto O Mal-Estar na Civilização (1930). Além disso, tomaremos como referências da representação feminina para a protagonista do conto em estudo, a personagem Sara, do Antigo Testamento, Sofia, personagem do romance Atire em Sofia, de Sônia Coutinho (1989) e Penélope, personagem clássica de Homero.
\end{abstract}

Palavras-chave: Psicanálise. Estudos de Clarice Lispector. Figurações do Feminino.

\begin{abstract}
The present article intends to analyze the short story $A$ fuga, by Clarice Lispector, written in 1940 and published in 1979 in $A$ bela e e a fera (1979), in the light of the Freudian concepts of the principle of pleasure and the principle of reality and other ideas also present in "Civilization and its discontents" (1930). Besides, references of the feminine representation are taken for the study of the protagonist, such as Sarah, from the Old Testament, Sofia, character of Atire em Sofia, by Sônia Coutinho (1989) and Penelope, classical character by Homer.
\end{abstract}

Keywords: Psychoanalysis. Studies on Clarice Lispector. Representations of the feminine.

Os desejos são fantasmas que se diluem, mal se acende a lâmpada do bom senso (LISPECTOR, 1992, p.78).

A psicanálise constitui-se como um campo do conhecimento que, assim como a literatura, tem por matéria primordial a linguagem. Dessa forma, a teoria psicanalítica vem se apresentando como um arsenal teórico de efetivo aproveitamento nos estudos literários. Ao mapear o funcionamento dos mecanismos psíquicos do homem, Sigmund Freud (1856-1939) também nos legou um importante operador de leitura para os textos

* Professora Titular da Universidade Estadual de Feira de Santana, Doutora em Teorias e Críticas da Literatura e da Cultura, UFBA.

** Professora Adjunta da Universidade Estadual de Feira de Santana, Doutora em Teorias e Críticas da Literatura e da Cultura, UFBA. 
literários, uma vez que as tramas narrativas e, sobretudo, a subjetividade das personagens podem ser lidas também através da teoria freudiana e de seus desdobramentos. Dedicadas a compreender as complexidades da condição humana, as teorias psicanalíticas compartilham dessa tarefa com as artes literárias, na tentativa de decifração constante dos anseios da humanidade.

O presente trabalho se propõe a analisar o conto $A$ Fuga, do livro $A$ Bela e a Fera (1979), da escritora Clarice Lispector, à luz dos conceitos freudianos do Princípio do Prazer e do Princípio da Realidade e outras ideias também desenvolvidas no texto O MalEstar na Civilização (1930). Além disso, tomaremos como referências da representação feminina e como modelos de análise para a protagonista do conto em estudo, a personagem Sara, do Antigo Testamento, Sofia, personagem do romance Atire em Sofia, de Sônia Coutinho (1989) e Penélope, personagem clássica de Homero.

\section{MULHERES EM REDE - OS FIOS DO TEAR CLARICIANO}

A epígrafe que abre esse trabalho: "Os desejos são fantasmas que se diluem mal se acende a lâmpada do bom senso", aparece com um ar despretensioso no centro da narrativa em análise, e parece delinear uma pista ou caminho de leitura para uma das possíveis compreensões do texto. Temos no binômio desejo/bom senso um dos pilares do conto em questão e, talvez, um tema central das personagens do universo clariceano.

Vale lembrar que, pela própria etimologia da palavra conto, do latim computu $(m)$, tudo é contado, computado, ou seja, nenhuma palavra está no texto de modo gratuito. Entendemos que a frase aponta para um dos aspectos centrais da temática: a condição da mulher casada que se vê dividida entre continuar desempenhando o papel que lhe foi atribuído ao longo dos tempos, como esposa, mãe e mantenedora do lar, baseado no papel bíblico referencial de Sara, esposa de Abraão, patriarca do Antigo Testamento, ou sucumbir aos desejos de desbravar o mundo extramuros, rasgando o seu papel secular e desafiando as leis sociais, como fez Sofia, personagem-título do romance Atire em Sofia (1989), da autora baiana Sônia Coutinho (1939-2013), que foge da sua condição de mãe e esposa, aventurando-se por outros caminhos e que, por conta disso, recebe o desprezo dos seus e o julgamento impiedoso da sociedade.

Esse é o dilema da personagem central de A Fuga, Elvira, praticamente única personagem do texto, protagonista de uma agonia solitária. Vale lembrar que, também etimologicamente, protagonista é aquele que primeiro agoniza, aquele que luta. A luta é silenciosa, porém representativa de um sem número de mulheres, as ditas mulheres bem casadas. Mais uma vez, vale lembrar a gênese estrutural do conto que, segundo Massaud Moisés (1974), possui um só conflito ou uma única célula dramática que, nessa narrativa, é simbolizada pela agonia de Elvira, que em sua fuga, sob o peso de doze anos de casamento que lhe parecem doze séculos, acaba voltando para casa, após uma longa reflexão, em que vencem o medo e um suposto dever social de esposa.

Um olhar atento à narrativa clariceana revela um desfile de personagens femininas se debatendo nessas fronteiras de aço invisível, que dividem o universo sólido e acomodado de Sara, protótipo da esposa, do universo reconfigurado por Sofia, que quebra 
com as expectativas sociais. Seguindo esse perfil do feminino em conflito, temos ainda, entre outras, Ana, em Amor, Laura, em A Imitação da Rosa (ambos de Laços de Família); Carla, de $A$ Bela e a Fera ou a Ferida Grande demais, também de A Bela e a Fera, que, por caminhos diferentes sofrem do mesmo problema: corresponder à imagem esperada (Sara), mesmo quando os espelhos e o ensimesmamento acusam as fraturas (Sofia).

Destacamos a recorrência e a preferência da autora, que problematiza em suas obras o mundo feminino sob variadas nuances, dentro da perspectiva das mudanças que o universo da mulher sofreu na segunda metade do século vinte, especialmente com relação aos papeis sociais e às possibilidades de mobilidade e conquista. Um panorama que desestabiliza um quadro de séculos e que, apesar de rasurar o papel das Saras, não fornece garantias para aquelas que desejam ser Sofias. A propósito desse impasse, vejamos o que diz Marina Colasanti em Mulher daqui pra frente:

[...] somos mutantes, mulheres em transição. Como nós, não houve outras antes. E as que vierem depois serão diferentes. Tivemos a coragem de começar um processo de mudança. E porque ainda está em curso, estamos tendo que ter a coragem de pagar por ele...Saímos de um estado que, embora insatisfatório, embora esmagador, estava estruturado sobre certezas. Isso foi ontem. Até então não duvidávamos do seu papel. Nem homens, nem muito menos mulheres.... Mas essa certeza nós a quebramos para poder sair do cercado. (COLASANTI, 1981, p.14)

O texto de Lispector é construído sobre o movimento de fuga de Elvira, em que a personagem tenta quebrar o "cercado", imagem que representa a sensação de prisão a que está submetida. Elvira oscila entre o dever de esposa a que se sente obrigada, e a liberdade, representada na imagem do mar sem fundo que contempla em sua saída pela noite do Rio de Janeiro e na desejada viagem de navio que se torna impossível para ela: "[...] Doze anos pesam como quilos de chumbo e os dias se fecham em torno do corpo da gente e apertam cada vez mais" (LISPECTOR, 1992, p. 81). Ou seja, o cercado, ou o vínculo do casamento de doze anos, que na imagem acima descrita pressiona e efetivamente cerca seu corpo, permanece em torno de Elvira. Desse modo, duas imagens se delineiam em seu pensamento: a realidade a que está ligada, em suas dimensões social e psicológica e seu desejo de liberdade, fonte de prazer.

A teoria freudiana apresenta dois conceitos que podem iluminar a compreensão deste conflito: o Princípio do Prazer e o Princípio da Realidade, que podemos entender da seguinte maneira: o Princípio do Prazer (PP) é um dos princípios que regem o funcionamento mental: a atividade psíquica, no seu conjunto, tem por objetivo evitar o desprazer ou sofrimento e proporcionar o prazer. Na medida em que o desprazer está ligado ao aumento das quantidades de excitação e o prazer, à sua redução, o princípio do prazer é um princípio econômico.

O Princípio da Realidade (PR) forma par com o princípio do prazer, modificandoo. $\mathrm{Na}$ medida em que consegue impor-se como princípio regulador, a procura da satisfação já não se efetua pelos caminhos mais curtos, mas pelos desvios e adia os seus resultados em função das condições impostas pelo mundo exterior. Retomando a epígrafe, em que o bom senso acende a luz sobre os fantasmas do desejo, dissipando-os, 
podemos entender que o PP corresponde ao desejo de liberdade e o PR representa o bom senso ou as convenções sociais. Assim, o segundo funciona como regulador do primeiro, ou seja, o princípio da realidade exterior, exigente, funciona como filtro do desejo de satisfação primitiva, regendo as ações e de certa forma restringindo ou adaptando os desejos.

No conto em estudo, é como se Sofia, imagem da mulher que rompe o cerco, e Sara, símbolo da esposa tradicional, mais uma vez se confrontassem. Ao final, temos a vitória da segunda, ou seja, o PR cassa a voz do PP. Elvira, dona de casa, é esposa de um marido bem-sucedido, "sólido, bom e que nunca erra". Incapaz de erro por representar o que a sociedade espera de um homem ou isento de qualquer erro ou culpa por ser homem? O marido, sem nome no texto, identifica-se com o próprio "bom senso", expressão que se liga à sensatez e aceitação dos padrões e papeis socialmente referendados: "Por que é que os maridos são o bom senso?” (LISPECTOR, 1992, p. 78)

Ao empreender sua fuga do sólido "Lar de Elvira", como a personagem mesma denomina, e provar um pouco de liberdade, Elvira tem medo e, chamada à razão pelo Princípio da Realidade, retoma a sua condição de mulher bem casada, sem que ninguém perceba a sua odisséia. Uma das ironias da narrativa é que apenas a personagem sabe de sua suposta fuga, não há testemunhas de sua saída transgressora. Assim é a ação reguladora do Princípio da Realidade sobre o Princípio do Prazer: Elvira rapidamente enumera em sua mente aspectos práticos da fuga que passa então a ver como obstáculos. Ela que poucas horas antes vislumbrava na viagem pelo mar sua liberdade, retrai-se e esconde novamente sua vontade de viver outra vida. Mente sobre sua saída para o marido e deita-se para dormir, cumprindo sua rotina. O Princípio do Prazer sucumbe à economia do Princípio da Realidade. Este é capaz de oferecer segurança e proteção contra o novo que, irrompendo com a força do desconhecido, desafia o ego.

\section{ENTRE A MACIEZ DA SEDA E A DENSIDADE DO CHUMBO}

Elvira estava casada havia 12 anos; o tempo de um sólido casamento que pesava como "quilos de chumbo". Ao contrário da maciez da seda, símbolo dos 12 anos de casamento, esse tinha a densidade do chumbo. Este peso se assemelha para ela a uma grande âncora a puxá-la para baixo, tornando-a inerte e cada vez mais fixada ao seu papel doméstico. Vale notar que a imagem do casamento como âncora a mantê-la presa no mar, sem poder experimentar de sua imensidão, contrasta com outras imagens que Elvira gera em sua reflexão, como quando contempla a água escura, imaginando o fundo do mar, tão imenso; a imagem do navio que viaja livre pelos oceanos, ou do homem imaginado na infância, a quem a gravidade não podia conter e que se movia pelo globo com toda liberdade e fluidez.

Evando Nascimento (2012) lembra que as protagonistas clariceanas empreendem monólogos interiores que constituem "passagens arriscadas por planos imanentes da existência, visando a transcender justamente a imanência pré-datada e predadora, dado culturalmente predeterminado". 
Assim, a resolução de fazer a travessia do pensamento para o mundo externo surge no texto a partir de um recurso próprio da escritura clariceana, a epifania, ou momento de ampliação da consciência, um insight. Este é compreendido como um momento de revelação interior, dotado de mistério, momento em que um elemento qualquer do ambiente externo, geralmente algo prosaico, ganha um novo e inusitado significado perante os olhos da personagem, numa espécie de tomada de consciência de seu estado de opressão e falta de liberdade que bruscamente se instala:

Abre a boca e sente o ar fresco inundá-la. Por que esperou tanto tempo por essa renovação?
Só hoje, depois de doze séculos. Saíra do chuveiro frio, vestira uma roupa leve, apanhara um
livro. Mas hoje era diferente de todas as tardes dos dias de todos os anos. Fazia calor e ela
sufocava. Abriu todas as janelas e as portas. Mas não: o ar ali estava imóvel, sério, pesado.
Nenhuma viração e o céu baixo, as nuvens escuras, densas. Como foi que aquilo aconteceu?
A princípio apenas o mal-estar e o calor. Depois qualquer coisa dentro dela começou a
crescer. De repente, em movimentos pesados, minuciosos, puxou a roupa do corpo,
estraçalhou-a, rasgou-a em longas tiras. O ar fechava-se em torno dela, apertava-a. Então um
forte estrondo abalou a casa. Quase ao mesmo tempo, caiam grossos pingos d'água, mornos
e espaçados (LISPECTOR, 1992, p. 79).

Nesse trecho podemos observar que, exatamente como Ana, Laura e Carla, personagens já citadas de outros contos, a revelação de Elvira acontece pela tarde, hora em que o lar se acomoda, tudo está calmo, porque as tarefas da casa já foram cumpridas, e os pensamentos se tornam alados através da presença simbólica e subversiva de um livro, incumbindo-se de abalar aquela realidade que parecia tão firme. A quietude da casa inquieta a "dona da casa", que parece apenas esperar pelas próximas demandas domésticas a serem cumpridas.

Nos papeis tradicionais, a mulher parece se incumbir apenas do aspecto prático ou doméstico da família e o homem, dos trabalhos que exigem sabedoria, conhecimento ou decisão. Nessa perspectiva, o pensamento da mulher, ignorado ou censurado, passa a ser um reino reprimido, mas, ao mesmo tempo, um de seus espaços de liberdade. Sentada na calma da tarde, Elvira fisicamente associa seu estado de cerceamento com o calor que a sufoca. De tal modo se sente oprimida, que tira suas roupas, rasgando-as; deste modo, simbolicamente despe-se do figurino de seu papel cristalizado de esposa e dona de casa.

Assim que executa a libertação das roupas que a apertam e sufocam, um estrondo ecoa, marcando o gesto de ruptura e culminando com a chuva, em "pingos grossos, mornos e espaçados". A água, muito presente em toda a simbologia das narrativas de Lispector, é signo da vida na sua origem, e inaugura a vida que Elvira teria lá fora, como um batismo: "Bem, as coisas ainda existem", pensa a personagem. Conforta-se com o pensamento de que o mundo permanecerá como sempre; sua ruptura ou quebra interna não desfará todas as coisas. Naquele momento ela constata que é possível haver uma vida diferente, além daquela que conhece.

Neste processo de busca de uma saída de um estado para outro, ou de um simples refúgio, podemos observar também as outras personagens clariceanas: Laura e Carla são casadas, tem bons maridos e lares bem estruturados onde não lhes falta nada, porém, falta vida a esses lares "perfeitos". Carla foge da consciência desse estado ao manter-se como 
um adorno, faz da beleza irretocável o seu refúgio, torna-se seu próprio mundo. Ana foge pelos pensamentos, criando um mundo só seu. Laura escapa através da loucura, o ilogismo é a sua libertação.

Já Elvira consuma concretamente sua partida, mesmo que por algumas horas: três horas de fuga para doze anos de casamento. Ao viver essas horas intensamente, via-se já liberta: "Eu era uma mulher casada e agora eu sou uma mulher". Essa passagem dá conta de um longo processo de despersonificação, que a fez deixar de ser uma mulher, para ser a mulher de alguém. Como um exemplo literário curioso sobre o patriarcalismo exercido secularmente, temos a Carta de Guia de Casados, escrita pelo português D. Francisco Manuel de Melo, no século XVII, uma espécie de receituário para o nobre que desejava se casar. A obra elenca diversas características para a esposa ideal: entre elas, a esposa teria que saber menos, ter menos e ser menos que o marido, ou seja, teria que ocupar um lugar sempre inferior ao marido, caracterizando uma total dependência: "Os que casam com mulheres maiores no ser, no saber, e no ter, estão em grandíssimo perigo" (MELO, 1971, p.24) diz o autor português sobre o casamento.

Mesmo habitando o século XX, as personagens de Clarice Lispector citadas neste estudo ocupam um lugar rigidamente fixado. Mas questionam a si mesmas e ao seu lugar social, por seu principal traço: o pensamento. Para Evando Nascimento (2012), trata-se de uma "literatura pensante", em que a autora problematiza as questões da mulher, de modo a propor, ressignificar e reconstruir conceitos, ainda que, ao final da narrativa, se produza apenas o pensamento problematizador e não uma solução para o problema da personagem.

\section{3 ÚLTIMOS FIOS - A ESCOLHA DE PENÉLOPE}

Deste modo, nos vemos diante da escolha de Elvira: voltar para casa, mesmo depois da experiência de libertação ao estar na rua, da contemplação do mar, dos planos de viagem no navio. Numa série de pensamentos que para ela tem o peso de verdades ou constatações, avalia que não é capaz de concretizar a viagem e a vida de liberdade. Seu pensamento se volta para o dever conjugal, para a expectativa que a sociedade tem acerca do papel da esposa; lembra-se que poderia ser vista por um dos amigos do marido e isso poderia prejudicar seus negócios:

Mas ela não tem suficiente dinheiro para viajar. As passagens são tão caras. E toda aquela chuva que apanhou, deixou-lhe um frio agudo por dentro. Bem que pode ir a um hotel. Isso é verdade. Mas os hotéis do Rio não são próprios para uma senhora desacompanhada, salvo os de primeira classe. E nestes pode talvez encontrar algum conhecido do marido, o que certamente lhe prejudicará os negócios. Oh, tudo isso é mentira. Qual a verdade? (LISPECTOR, 1992, p. 80).

O trecho acima confirma a força do estigma social que recai sobre a mulher "bem casada". Ela deve sempre se comportar de maneira que o seu perfil jamais interfira na imagem do seu marido e de sua família, sempre espelhando a imagem do bom senso e do comedimento. Em vez do olhar voltado para si, em que seria capaz da viagem, Elvira vê 
a si mesma agora com os olhos da sociedade: sozinha, seria uma "senhora desacompanhada", ou seja, uma mulher que carece de um marido ou um homem, alguém que possa dar-lhe legitimação como mulher direita ou honesta. Seu valor como pessoa é transferido para a presença ou ausência do marido. Sem o casamento, haveria sobrevivência? Mesmo reconhecendo que tudo que acaba de elaborar é mentira, Elvira se questiona: Qual a verdade? Mas sua única verdade, como enuncia a seguir, são os doze anos de casamento que funcionam como peso e âncora.

Para Freud, a situação de infelicidade provém de três elementos diferentes, limitando a efetivação da busca do princípio do prazer. Estes são os aspectos biológicos, ligados à saúde e à decadência do corpo; aspectos sociais ou originados por forças externas, como a guerra; e os psicológicos, ou relacionais. Para ele, nossas possibilidades de felicidade sempre são restringidas por nossa própria constituição. Já a infelicidade é muito menos difícil de experimentar. Também o sofrimento que provém da fonte dos aspectos relacionais é apontado como o que provavelmente nos seja mais doloroso (FREUD, 1974, p.33). Podemos perceber que Elvira sofre por pertencer a um condicionamento social que a despersonaliza e limita. Mas sua fonte principal de sofrimento está ligada à força relacional que se sobrepõe à sua individualidade: o marido, que funcionando dentro de uma relação de poder estabelecida pelos séculos, impede-a de pensar ou agir:

Porque seu marido tinha uma propriedade singular: bastava sua presença para que os menores movimentos de seu pensamento ficassem tolhidos. A princípio, isso lhe trouxera certa tranquilidade, pois costumava-se cansar-se pensando em coisas inúteis, apesar de divertidas... Os dias se derretem, fundem-se e formam um só bloco, uma grande âncora. E a pessoa está perdida. Seu olhar adquire um jeito de poço fundo (LISPECTOR, 1992, p. 78).

Enfim, repetem-se os velhos papéis da mesma história, o homem é o provedor do lar e a mulher, a mantenedora desta estrutura. Penélope precisa fiar para que Ulisses guerreie. No retorno para o lar, só Elvira havia mudado; a epifania é solitária, a travessia é intima e intransferível, pois tudo estava em seus lugares de origem, exceto as suas inquietações. O marido já deitado, nada de novo. Elvira veste um pijama de flanela azul macio para aquecer-se, combatendo a frieza que a consumia. Pede ao marido que apague a luz; ele torce o comutador, gesto significativo, uma vez que ele é quem controla o ritmo de sua vida. Ele mecanicamente a beija e pede que o acorde pela manhã, na completa certeza de que tudo continuaria como sempre foi. Assim, ele renova a posição de Elvira como responsável pelo correto funcionamento do cotidiano. Ela chora, fecha os olhos e ajeita-se na cama, procurando uma melhor posição para o corpo, já que a alma permanece em desassossego. Sente a lua cobri-la vagarosamente. Ao longe, seu navio parte e seu itinerário impossível se dissipa na bruma da noite.

E assim, a razão desautoriza o desejo, estabelece-se a vitória de Logos, razão e bom senso, sobre Eros, o princípio de vida; a força da realidade social sobre a possível satisfação do eu. Ao final, o leitor se volta para o título: houve fuga? Podemos afirmar que sim, na perspectiva do universo clariceano, conforme explica Nádia Gotlib: 
tempo histórico, mergulhando numa outra realidade que se eterniza e se repete no gosto doce e amargo das coisas de que somos feitos- Essa experiência- de passeio pelo jardim, ou pelo Calçadão do Rio de Janeiro (inclusão nossa) ou da leitura dessa Clarice - realça a inevitável convivência com a realidade da condição humana (GOTLIB, 1995, p. 83).

Elvira mergulhou numa outra realidade ao fazer a sua travessia epifânica, experimentando algumas horas de liberdade. Conforme Nunes (1995), esses momentos epifânicos, em que se constrói no texto clariceano uma nova compreensão ou uma libertação, servem para "assinalar o limite que separa o dizível do ser indizível”. Ou seja, ainda que imersa na sua solidão e que só ela tenha sido testemunha de seu movimento interno, mesmo sem uma concretização externa, um gesto de liberdade e de coragem se realizou. Este é o ser que busca liberdade fora do Mal-estar gerado pela civilização. A fuga, vivida precariamente, produziu para Elvira instantes de intensa alegria. Ainda que por uma tarde, a personagem contrariou a dinâmica do sofrimento apontada por Freud e fez com que o desejo agisse sobre a realidade. Assim entre Sara e Sofia, temos Elvira, uma Penélope que continuará a tecer para que Ulisses guerreie, porém, uma Penélope diferente, que ousou revelar os avessos do bordado, expondo os fios que compõem sua intricada trama.

\section{REFERÊNCIAS}

COLASSANTI, Marina. Mulher daqui pra frente. Rio de Janeiro: Nórdica, 1981.

FREUD, Sigmund. Obras Completas. São Paulo: Imago, 1974.

GOTLIB, Nádia Battella. Clarice -Uma vida que se conta. São Paulo: Ática, 1995.

GOTLIB, Nádia Batella. (Org.) A mulher na literatura. Belo Horizonte. ANPOLL: UFMG, 1990.

LISPECTOR, Clarice. Laços de Família. Rio de Janeiro: Nova Fronteira, 1983.

LISPECTOR, Clarice. A Bela e a Fera. Rio de Janeiro: Francisco Alves, 1992.

MELO, Francisco Manuel de Melo. Carta de Guia de Casados. Lisboa: Editorial Verbo, 1971.

MOISÉS, Massaud. Dicionário de Termos Literários. São Paulo: Cultrix, 1974.

NUNES, Benedito. O drama da linguagem: uma leitura de Clarice Lispector. 2ed. São Paulo: Ática, 1995. 
NASCIMENTO, Evando. Clarice Lispector: uma literatura pensante. Rio de Janeiro, Civilização Brasileira, 2012.

Recebido em: 17/03/2017

Aprovado em: 25/05/2017

Publicado em: 01/06/2017 